
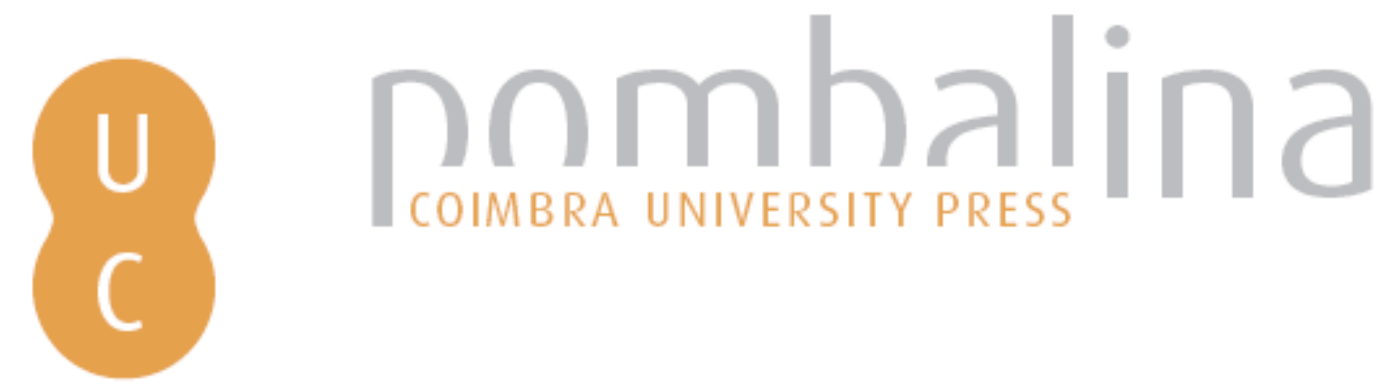

\title{
Turismo, sustentabilidade e ambientes de montanha: o caso do Piódão: reflexões em torno das perspectivas dos visitantes
}

Autor(es): $\quad$ Correia, Juliana; Carvalho, Paulo

Publicado por: Imprensa da Universidade de Coimbra

URL

persistente: URI:http://hdl.handle.net/10316.2/30788

DOI: $\quad$ DOI:http://dx.doi.org/10.14195/978-989-26-0244-8_27

Accessed : $\quad$ 26-Apr-2023 16:17:41

A navegação consulta e descarregamento dos títulos inseridos nas Bibliotecas Digitais UC Digitalis, UC Pombalina e UC Impactum, pressupõem a aceitação plena e sem reservas dos Termos e Condições de Uso destas Bibliotecas Digitais, disponíveis em https://digitalis.uc.pt/pt-pt/termos.

Conforme exposto nos referidos Termos e Condições de Uso, o descarregamento de títulos de acesso restrito requer uma licença válida de autorização devendo o utilizador aceder ao(s) documento(s) a partir de um endereço de IP da instituição detentora da supramencionada licença.

Ao utilizador é apenas permitido o descarregamento para uso pessoal, pelo que o emprego do(s) título(s) descarregado(s) para outro fim, designadamente comercial, carece de autorização do respetivo autor ou editor da obra.

Na medida em que todas as obras da UC Digitalis se encontram protegidas pelo Código do Direito de Autor e Direitos Conexos e demais legislação aplicável, toda a cópia, parcial ou total, deste documento, nos casos em que é legalmente admitida, deverá conter ou fazer-se acompanhar por este aviso.

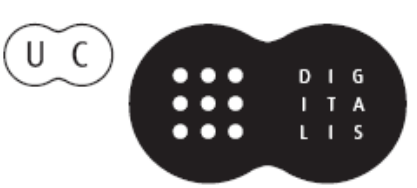




\section{TRUNFOS DE UMA}

\section{EOGRAFIA ACIVA}

\section{DESENVOLVIMENTO LOCAL,}

AMBIENTE,

ORDENAMENTO

E TECNOLOGIA

Norberto Santos

Lúcio Cunha

COORDENAÇÃO 
Juliana Correia ${ }^{1}$, Paulo Carvalho ${ }^{2}$

${ }^{1}$ Departamento de Geografia, Universidade de Coimbra

${ }^{2}$ Departamento de Geografia e CEGOT, Universidade de Coimbra

\section{TURISMO, SUSTENTABILIDADE E AMBIENTES DE MONTANHA: O CASO DO PIÓDÁO. REFLEXÓES EM TORNO DAS PERSPECTIVAS DOS VISITANTES}

\section{TURISMO, PLANEAMENTO E DESENVOLVIMENTO SUSTENTÁVEL}

A importância crescente da dimensão territorial no quadro das políticas públicas e o seu reconhecimento como eixo vertebrador do desenvolvimento sustentável contribuíram para repensar o valor estratégico do planeamento em diversas actividades alicerçadas na utilização de recursos finitos e, em alguns casos, não renováveis, como é o caso do turismo (Carvalho, 2009).

Apesar da dimensão global do turismo, este fenómeno desenvolve-se também à escala local com implicaçóes directas e indirectas sobre os territórios e a vida das pessoas (Hall, 2008). O crescimento acentuado do número de turistas (nacionais e estrangeiros), a expressão urbanística do lazer e do turismo, o consumo desenfreado de recursos, a capacidade de induzir o desenvolvimento de outros sectores relevantes como, por exemplo, o comércio, os transportes, as actividades seguradoras e financeiras (Costa et al., 2004), entre outros factores, conduziram à consciencialização e à necessidade de repensar a actividade turística segundo uma óptica alicerçada na relação qualidade/continuidade, e reforçam a importância da sustentabilidade e do planeamento da actividade turística na agenda das principais políticas e programas que preconizam o desenvolvimento territorial.

Por outro lado, as características do actual mercado turístico (um mercado agressivo devido ao crescente número de destinos que aí operam (e/ou querem operar) e à qualidade que apresentam destinos já consolidados), "colocam barreiras à entrada de novos concorrentes e exigem que os destinos emergentes encontrem novas formas de competitividade e, consequentemente, formas inovadoras de gestão sustentada" (Mota et al., 2008: 3088).

Se reflectirmos no âmbito dos espaços rurais e de montanha, com problemas acentuados no plano demográfico, económico e social (Moreno, 1999; Carvalho, 2005; Price, 2007), o planeamento assume um papel ainda mais importante e imprescindível na definição das estratégias de desenvolvimento a implementar e na ponderação dos custos e benefícios decorrentes do desenvolvimento vinculado ao lazer e ao turismo (Butler et al., 1998; Hall et al., 2003).

O turismo quando náo planeado pode acarretar desequilíbrios muito fortes nos lugares de destino, correndo o risco de tornar-se vítima do seu próprio êxito se náo se orientar e desenvolver na óptica da sustentabilidade, de modo que o seu crescimento descontrolado 
pode colocar em risco a biodiversidade, os recursos naturais, o património cultural, e o bem-estar e qualidade de vida da população local.

Neste sentido, reconhecendo o planeamento como uma ferramenta indispensável das políticas de promoção do desenvolvimento sustentável, podemos afirmar que a transposiçáo dos seus princípios nucleares para o campo do turismo pretende, no essencial, salvaguardar recursos, criar e distribuir benefícios, e envolver as populaçóes locais. Por outras palavras, a promoção do turismo sustentável deve corresponder à implementação de actividades destinadas à satisfaçáo das necessidades dos turistas mas que, ao mesmo tempo, contribuem para a melhoria da qualidade de vida da populaçáo local, segundo uma perspectiva de médio e longo prazo.

Ferreira (2006), citando a Organização Mundial do Turismo (OMT), destaca vários princípios de actuação que estão na base do desenvolvimento do turismo sustentável, e que se tornam ainda mais pertinentes, quando se preconizam acçóes de desenvolvimento em áreas protegidas ou ambientalmente frágeis como são as montanhas. A abordagem proposta pela OMT enfatiza componentes como a participaçáo esclarecida de todos os parceiros e uma liderança forte no sentido da construção de consensos de actuaçáo, a necessidade de uma permanente monitorização de impactes de forma a introduzir medidas preventivas/correctivas sempre que necessário, e por fim, a recomendaçáo de que um turismo sustentável deverá proporcionar um elevado grau de satisfação nos turistas e uma experiência de viagem gratificante, para além de os incentivar a desenvolver, também, boas práticas.

Assumindo que planear no contexto da actividade turística é propor medidas de maximização das suas potencialidades e de aproveitamento das oportunidades que lhe são proporcionadas pela conjuntura em que se insere (Ladeiras et al., 2005), é entáo do estabelecimento de um correcto planeamento do turismo nas áreas de destino que resultará o aparecimento de vantagens competitivas face aos outros destinos concorrentes. Por outro lado, a actividade turística deverá ser equacionada de forma estratégica, isto é, segundo os princípios da sustentabilidade, de modo a garantir que a sua implementaçáo e continuidade a longo prazo num determinado território não coloque em risco os seus pilares estruturantes (os recursos turísticos). Por esta razão, torna-se importante a definição de modelos de planeamento da actividade turística (Inskeep, 1991; Burns, 2004; Hall, 2008), das acçóes a concretizar, dos resultados (positivos ou negativos) que essas acçóes podem geram, e ainda a avaliação do sucesso adquirido (Page e Hall, 2003; Partidário, 2006; Baumgartner, 2006).

Importa, então, reter que o planeamento da actividade turística "ocorre sob uma variedade de formas (desenvolvimento, infra-estruturas, uso do solo e dos recursos, organização, recursos humanos, promoção e marketing), estruturas (diferentes governos, organizaçóes quase e não governamentais), escalas (internacional, transnacional, regional, local, de lugar) e em diferentes tempos (para desenvolvimento, implementação, avaliação, e o atingir satisfatório dos objectivos de planeamento" (Henriques, 2003: 207).

A recente aprovação da Lei de Bases do Turismo (Decreto-Lei no 191/2009 de 17 de Agosto), que consagra os princípios orientadores e os objectivos da Política Nacional de Turismo, reconhece o Plano Estratégico Nacional do Turismo (2007) como o instrumento de enquadramento das políticas públicas de turismo, e identifica a sustentabilidade, a transversalidade e a competitividades como os seus princípios gerais.

De acordo com este documento estruturante, a sustentabilidade traduz-se na adopção de políticas que incentivem a fruição e a utilização dos recursos ambientais com respeito 
pelos processos ecológicos, contribuindo para a conservação da natureza e da biodiversidade; o respeito pela autenticidade social e cultural das comunidades locais, visando a conservação e a promoção das suas tradições e valores; a viabilidade económica das empresas como base da criação de emprego, de melhores equipamentos e de oportunidades de empreendedorismo para as comunidades locais.

A transversalidade do sector traduz a necessidade de articular as várias políticas sectoriais que interferem no desenvolvimento turístico, designadamente nos domínios da segurança e da protecção civil, do ambiente, do ordenamento do território, dos transportes e das acessibilidades, das comunicaçóes, da saúde e da cultura.

O princípio da competitividade traduz-se na adopçáo de políticas de ordenamento do território que potenciem os recursos naturais e culturais como fontes de vantagem competitiva para os destinos e produtos turísticos, entre outras medidas.

Em síntese, o planeamento do turismo é uma ferramenta fundamental no esteio das directrizes, metas e linhas de acção que enquadram as políticas de turismo, e um instrumento decisivo para implementar o turismo sustentável, nomeadamente a capacidade de contribuir para a melhoria da qualidade de vida e para promover o seu desenvolvimento sustentável em termos ambientais, económicos e sociais.

\section{O PIÓDÃO TURÍSTICO: PLANOS, INTERVENÇÓES E VISITANTES}

A segunda parte desta reflexão aparece centrada na aldeia do Piódão (Serra do Açor / Cordilheira Central). Uma leitura geográfica de grande angular centrada neste microterritório de montanha (do concelho de Arganil - Pinhal Interior Norte), revela o peso histórico de problemas como o isolamento, a escassez de recursos, a marginalização (no âmbito do poder político), o despovoamento (entre 1960 e 2001, o Piódão perdeu quase $80 \%$ da população residente), o envelhecimento (em 2001, 44\% dos residentes na freguesia apresentavam 65 ou mais anos e apenas $10 \%$ eram jovens), o baixo nível de escolaridade, e o abandono (nomeadamente a paisagem rural, por via do declínio acentuado das actividades tradicionais).

Contudo, é necessário referir também que a partir da segunda metade dos anos 70 (século XX), um conjunto de acontecimentos encadeados, no contexto da patrimonialização e da turistificação, com o envolvimento de entidades públicas, privadas e associativas, assinalam a transição funcional do Piódão e a profunda mutação da sua imagem (Carvalho e Correia, 2008).

A génese e a evolução do Piódão turístico têm como eixos incontornáveis a classificação da aldeia como Imóvel de Interesse Público (1978), o Plano de Desenvolvimento e Requalificação da Aldeia (1987), o Programa das Aldeias Históricas de Portugal (1994-1999), as Acções Inovadoras de Dinamização das Aldeias (2000-2006), o Plano de Acção Integrada para a Freguesia do Piódão (2004), entre outras iniciativas (nomeadamente as relacionadas com o desenvolvimento rural).

Neste quadro de construção do Piódão turístico destacam-se as intervençóes em torno das Aldeias Históricas (1994-1999 e 2000-2006) que pretenderam integrar objectivos patrimoniais, económicos e sociais numa estratégia de desenvolvimento inovadora. As suas linhas de acção foram direccionadas para as infra-estruturas básicas, a salvaguarda e valorização do património (através de intervençôes ao nível das fachadas e coberturas das 
estruturas edificadas), a promoção e divulgação do território e a animação das economias locais (CCRC, 2002).

No caso do Piódão, o investimento total, segundo dados oficiais de 2002, foi de 5,5 milhôes de euros distribuído por 71 intervenções, das quais destacamos os equipamentos turísticos (designadamente a Estalagem da INATEL, com 3,8 milhóes de euros de investimento), as infra-estruturas básicas e a recuperação de fachadas e coberturas. Os efeitos locais destes programas são também visíveis no âmbito das novas actividades (comércio de artesanato, serviços de cafetaria, restauração e alojamento) e equipamentos (posto de turismo e museu) que conferem ao Piódão uma maior capacidade de atracção turística.

Assim, em face da crescente procura e utilização deste lugar de montanha, no âmbito do lazer e do turismo, que se verificou nos últimos anos, é pertinente conhecer os visitantes para compreender a dimensão turística do Piódão. Neste sentido apresentamos os resultados preliminares de um inquérito (por questionário), realizado entre Junho e Setembro de 2008, aos maiores de idade que se deslocaram ao Piódáo em veículo próprio, que permitiu conhecer as características dos visitantes, a experiência e a dimensão da visita, e a sua percepção e avaliação desta aldeia histórica.

O número de inquéritos validados (550) corresponde a uma amostra de 3,3\% dos visitantes/ano na última década (com base nos registos do posto de turismo do Piódão). A amostra é constituída por $67,5 \%$ de excursionistas (371 inquiridos) e 32,5\% de turistas (179 inquiridos), maioritariamente de nacionalidade portuguesa (92\%).

Em relação às características dos visitantes, a amostra revelou que $92,5 \%$ dos inquiridos residem em Portugal, repartidos por mais de nove dezenas de municípios (acentuada dispersão geográfica) e 7,5\% residem no estrangeiro (com destaque para o Brasil); 46,2\% dos visitantes apresentam idades entre os 30 e os 49 anos (esta classe tem maior preponderância entre os turistas, com 55,9\% das respostas); 44,1\% dos turistas apresentam habilitaçóes académicas de nível superior (patamar que no caso dos excursionistas diz respeito ao ensino básico); e a estrutura sócio-profissional é dominada pelos trabalhadores por conta de outrem (excepto funcionários públicos) - 31,1\%; reformados $(14,9 \%)$; e empresários e trabalhadores por conta própria $(11,6 \%)$.

O principal meio de transporte até à aldeia confirma a utilização preferencial do automóvel por $98 \%$ dos visitantes (tendência que não pode ser dissociada das características físicas que caracterizam estes lugares de montanha) e em ambiente familiar (88,2\%). Ainda assim, verificamos que a família assume maior expressão como companhia para os turistas $(95,0 \%)$ do que para os excursionistas $(84,9 \%)$, assim como notamos que os amigos são mais referenciados como companhia para os excursionistas $(15,1 \%)$ do que para os turistas (5,0\%).

Quanto à análise do alojamento (oferta, tipologia, número de noites e modo de reserva) que constitui o principal elemento diferenciador do nosso estudo (excursionistas e turistas), os inquéritos revelam que $73,2 \%$ dos turistas pernoitam na aldeia, preferencialmente, na Estalagem da Inatel (55,7\%) e na Casa da Padaria (TER) $(25,2 \%)$, com uma permanência média de 2,3 noites/turista. Para os turistas que optam por ficar alojados em outros lugares (26,8\%) com destaque para os concelhos de Arganil (39,4\%), Seia (13,2\%), Fornos de Algodres (10,5\%) e Covilhã (7,9\%), o hotel é a primeira opção de alojamento $(54,2 \%)$ seguido pelas unidades de turismo em espaço rural $(22,9 \%)$, com uma permanência média de 3,8 noites/turista. 
Ao questionar os nossos inquiridos acerca da sua frequência de visita ao Piódão e quais as principais dificuldades que sentiram durante a sua viagem, verificamos um maior peso da visita à aldeia pela primeira vez entre os turistas $(70,4 \%)$ comparativamente aos excursionistas $(62,8 \%)$, e constatamos que as principais dificuldades relacionadas com a viagem ao Piódão decorrem das vias de comunicação $(66,9 \%)$ no contexto da montanha (numa extensão de 30 a 40 quilómetros), designadamente o traçado sinuoso, o mau estado de conservação do piso e a sinalização deficitária.

$\mathrm{O}$ inquérito procurou igualmente compreender a relação existente entre os visitantes da aldeia do Piódão e as outras aldeias históricas, e permitiu verificar que o Piódão como a primeira aldeia histórica visitada assume maior relevância entre os turistas (70,4\%) do que nos excursionistas $(62,8 \%)$. Quanto à visita prévia de outras aldeias históricas, no caso dos excursionistas destacamos a aldeia de Monsanto $(41,6 \%)$ que assume igual predominância nas respostas dos turistas $(28,7 \%)$. As restantes aldeias históricas referidas pelos excursionistas, indicam numa posição secundária a vila de Almeida (16,8\%), seguida por Castelo Rodrigo (12,2\%) e Sortelha (11,3\%). Esta situação é também referida pelos turistas, com oscilaçóes percentuais pouco significativas.

A aldeia do Piódão aparece nas respostas dos nossos inquiridos como o principal destino de viagem (77\%). No entanto, foi ainda possível apurar um conjunto de outros lugares de interesse a visitar pelos excursionistas e pelos turistas. Cerca de $55 \%$ dos visitantes manifestaram vontade de conhecer, no próprio dia ou no dia seguinte, outros locais, designadamente a Fraga da Pena e a Mata da Margaraça (33,9\%), a Serra da Estrela $(12,9 \%)$, a Aldeia das Dez e o Santuário da Senhora das Preces (9,7\%) - a Mata da Margaraça, no contexto de proximidade do Piódão, faz parte da Rede Nacional de Áreas Protegidas, da Rede Natura 2000 e das Reservas Biogenéticas do Conselho da Europa.

Por último, importa sublinhar os principais elementos da percepção e avaliação da aldeia, segundo os visitantes (65\% conheceram a aldeia pela primeira vez). Quando questionados sobre o que mais gostaram da aldeia, os visitantes enfatizam o "conjunto" (76,7\%), ou seja, a unidade arquitectónica da aldeia e a sua integraçáo na paisagem, a paisagem natural (10,2\%), e os imóveis recuperados (5,3\%). Em sentido oposto, cerca de $74 \%$ dos visitantes referem dificuldades/problemas durante a visita, em particular os acessos viários $(35,6 \%)$, as dissonâncias arquitectónicas (12,2\%), os imóveis arruinados/abandonados (7,5\%) e outros problemas $(18,4 \%)$ como a falta de estacionamento, a abordagem por parte dos comerciantes/apelo à compra de produtos, e a sujidade de certos recantos da aldeia. É ainda de referir, que os turistas estão mais preocupados com as acessibilidades viárias $(46,4 \%)$ e também, embora com menos significado, com os imóveis arruinados/abandonados $(8,4 \%)$. Por sua vez, os excursionistas, revelam uma maior amplitude de respostas em termos de pequenas preocupaçóes como, por exemplo, a falta de caixotes para o lixo, a estalagem da INATEL e o atendimento no museu da aldeia.

É este, também, o alinhamento principal de sugestóes dos visitantes para melhorar as condiçôes de acolhimento do Piódão. Com efeito, as suas respostas manifestam preocupação com o potencial turístico e cultural da aldeia e a necessidade de promover alternativas para melhorar a qualidade de vida da população local, nomeadamente: a melhoria dos acessos viários (51,6\%), iniciativas de uniformização da aldeia (isto é, a eliminação de todas as dissonâncias arquitectónicas) e de recuperação dos imóveis que se encontram em estado de ruína ou abandono $(11,6 \%)$, a reconstrução do parque de estacionamento e da praia fluvial referidas por $7,6 \%$ e $5,6 \%$ dos inquiridos, respectivamente. Como "outras sugestóes" 
referidas pelos visitantes $(10,7 \%)$, destacamos a instalação de um serviço de multibanco, a construção de um posto de abastecimento de combustível, a inviabilização de propostas para aumentar o sector comercial da aldeia, a promoção de uma maior oferta de restauração, a existência de painéis informativos sobre a aldeia direccionados para o visitante, a maior oferta de alojamento e o alargamento do horário de funcionamento do posto de turismo.

Ainda assim, quando questionados sobre a intenção de voltar ao Piódão, 91\% dos nossos inquiridos responderem de forma positiva.

O nosso inquérito termina com uma questão importante que pretende analisar a capacidade de atracçáo do Piódão (que se procura afirmar como um destino turístico). Neste sentido, quando interpelados com a questão "Vai regressar à aldeia do Piódão?", os nossos inquiridos respondem, de forma inequívoca, em sentido positivo $(91,1 \%), 90,6 \%$ dos excursionistas e $92,2 \%$ dos turistas.

Em síntese, os resultados do inquérito permitiram concluir que o "Piódão turístico" assume um carácter mais direccionado para um "Piódão de excursionismo", uma vez que a amostra é constituída por $67,5 \%$ de excursionistas (371 inquiridos) e 32,5\% de turistas (179 inquiridos). Esta tendência dominante (excursionistas) assenta numa população de nacionalidade portuguesa $(91,6 \%)$, que permanece um reduzido período de tempo no Piódão e regressa na sua grande maioria ao domicílio $(74,9 \%)$ nesse mesmo dia.

Com o intuito de promover o bem-estar da população residente e melhorar as condiçóes de acolhimento dos visitantes, destacamos as recentes intervençôes de beneficiação e requalificação do Piódão ao nível dos acessos viários (com particular incidência no ramal de ligação Formarigo - Piódão, numa extensão de $15 \mathrm{~km}$ ), a ampliação da entrada da aldeia através da reorganização do estacionamento e do sentido de deslocação dos automóveis (com mais seis dezenas de lugares de estacionamento), a recuperação das margens da ribeira (que abre caminho para a reconstrução da piscina fluvial do Piódão).

Estas intervençôes, da responsabilidade da Câmara Municipal de Arganil (com um custo total de 2 milhóes de euros), vêm atenuar ou mesmo resolver alguns dos problemas que os nossos inquiridos referiram, e contribuir para uma renovada imagem da aldeia que reforçará a sua capacidade de atrair (ainda) mais visitantes.

\section{NOVAS JANELAS DE OPORTUNIDADE PARA O DESENVOLVIMENTO DO PIÓDÃO}

Por último, importa referir as novas janelas de oportunidade para o desenvolvimento do Piódão, que decorrem do actual período de programação e execução das políticas públicas, nomeadamente o PROVERE e o PRODER.

O PROVERE (Programa de Valorização Económica de Recursos Endógenos) é um instrumento desenvolvido pelo Ministério do Ambiente, do Ordenamento do Território e do Desenvolvimento Regional que pretende estimular iniciativas de melhoria da competitividade territorial de áreas de baixa densidade que visem dar valor económico aos recursos endógenos e singulares destes territórios (como o património cultural e natural). Alicerçados numa perspectiva de integração programática inovadora, os PROVERE centram-se no estabelecimento de parcerias, envolvendo actores públicos e privados (empresas, associaçôes empresariais, municípios, instituiçóes de ensino e de I\&D, agências de desenvolvimento regional, associaçóes de desenvolvimento local, entre outras instituiçóes relevantes), e congre- 
gam um conjunto de projectos subordinados à valorização económica de um recurso territorial emblemático.

A iniciativa Rede das Aldeias Históricas de Portugal é uma das oito candidaturas aprovadas pelo Programa Operacional da Região Centro (2007-2013) no âmbito das Acçóes Preparatórias do PROVERE. Este Plano apresentado pela Associação de Desenvolvimento Turístico das Aldeias Históricas pretende dar continuidade aos investimentos realizados nos últimos dois Quadros Comunitários de Apoio e consolidar a Rede das Aldeias Históricas como um produto turístico com potencial relevante no que diz respeito ao turismo cultural, turismo de natureza e turismo em espaço rural.

A definição de um novo modelo de gestão da marca "Aldeias Históricas de Portugal", sob responsabilidade desta Associação, é ainda complementado no âmbito das Estratégias de Eficiência Colectiva (EEC), por um recente programa de acçáo que apresenta como foco temático a Rede das Aldeias Históricas de Portugal e do Património Judaico. O PROVERE das Aldeias Históricas e do Património Judaico, centrado na Beira Interior Norte, Beira Interior Sul, Cova da Beira e Pinhal Interior Norte, é uma oportunidade para a geração de sinergias ao nível dos serviços turísticos oferecidos, tornando a associação de ambas as Redes (sem colocar em causa a identidade e especificidade de cada uma) num produto turístico mais atractivo, mais valorizado e reconhecido pelos mercados.

No contexto das candidaturas aprovadas no âmbito das Acçóes Preparatórias do PROVERE, e com particular interesse para o nosso caso de estudo, referimos também o programa de acção "BuY NATURE - Turismo Sustentável em Áreas Classificadas" coordenado pelo Instituto da Conservaçáo da Natureza e da Biodiversidade, com base numa rede de parceiros públicos e privados que se repartem pelas NUT III da Beira Interior Norte, Beira Interior Sul, Cova da Beira, Pinhal Interior Norte, Pinhal Interior Sul e Serra da Estrela, entre os quais se encontram a Agência para o Desenvolvimento Turístico das Aldeias do Xisto, a Associação das Aldeias Históricas de Portugal e a Naturtejo.

Esta iniciativa pretende potenciar os recursos endógenos do património natural das áreas classificadas de montanha da Região Centro (complementados pelo respectivo património cultural), através da implementação de uma estratégia de base territorial alicerçada no turismo de natureza, no desporto de natureza e no turismo activo, e procura afirmar-se como uma iniciativa que reforce a competitividade do território e promova uma abordagem sustentável no uso dos recursos endógenos assente num trabalho de parceria entre os agentes locais.

No âmbito do PRODER (Programa de Desenvolvimento Rural do Continente), o seu eixo 3 pretende dinamizar as áreas rurais através de duas medidas (3.1 e 3.2) direccionadas para a "Diversificação da economia e criação de emprego" e para a "Melhoria da qualidade de vida", respectivamente. A primeira é concretizada através de acçóes como, por exemplo, a diversificação de actividades na exploração agrícola (mediante actividades económicas de natureza não agrícola, em áreas como o turismo em espaço rural, o turismo de natureza, actividades associadas à caça e pesca em águas interiores, entre outras), e o desenvolvimento de actividades turísticas e de lazer (que inclui produtos turísticos, alojamento turístico de pequena escala nas modalidades de turismo em espaço rural e turismo de natureza, e infraestruturas de pequena escala tais como, centros de observação da paisagem, rotas/percursos, animação turística). A segunda inclui acções em dois domínios: a conservação e valorização do património rural (preservação, refuncionalização e valorização da cultural local), e os 
serviços básicos para a população rural, designadamente os serviços de apoio à infância, o acompanhamento domiciliário a idosos e deficientes, serviços itinerantes de apoio social, e serviços de animação cultural e recreativa de base local.

Neste contexto, a ADIBER (Associação de Desenvolvimento Integrado da Beira Serra) com o principal objectivo de dinamizar e promover a qualidade vida da Beira Serra (Arganil, Góis, Oliveira do Hospital e Tábua), publicou no passado dia 21 de Setembro de 2009, o $1^{\circ}$ Concurso para a recepção de candidaturas no âmbito do apoio financeiro concedido pelo PRODER, que terminará no dia 20 de Novembro de 2009. Este território ficará dotado de um instrumento de ajuda financeira na ordem dos 6,5 milhóes de euros para o desenvolvimento de projectos em diversas áreas e será gerido de acordo com a abordagem LEADER.

Por outro lado, no contexto do Programa Operacional da Regiáo Centro, no seu eixo 4 - "Protecção e Valorização Ambiental", destacamos ainda o projecto "Valorização Turística do Património Natural da Serra do Açor”, apresentado pela ADXTUR (Agência para o Desenvolvimento Turístico das Aldeias do Xisto), que envolve um custo estimado de cerca de 360 mil euros.

\section{REFERÊNCIAS BIBLIOGRÁFICAS}

Baumgartner, C. (2006): “A avaliação da sustentabilidade dos destinos turísticos”. In Careto, H, e Lima, S. (2006): Turismo e Desenvolvimento Sustentável - 1. Lisboa, GEOTA, pp. 81-91.

Burns, P. M. (2004): “Tourism Planning. A Third Way?”. Annals of Tourism Research, 30(1), pp. 24-43.

Butler, R. et al. (1998): Tourism and recreation in rural areas. Chichester, John Wiley \& Sons.

Carvalho, P. (2005): Património cultural e trajectórias de desenvolvimento em áreas de montanha. O exemplo da Serra da Lousã. Dissertaçáo de Doutoramento em Geografia, Faculdade de Letras da Universidade de Coimbra, Coimbra, pp. 657 (policopiado). Reeditado em 2009, com o título Património construído e desenvolvimento em áreas de montanha. O exemplo da Serra da Lousã, pela Câmara Municipal da Lousã, Lousã, pp. 657.

Carvalho, P. (2009): "Planeamento, redes territoriais e novos produtos turísticos eco-culturais". Proceedings $1^{s t}$ Cape Verde Congress of Regional Development. Ponta Delgada, APDR, 19 pp.

Carvalho, P. e Correia, J. (2008): “Turismo, património(s) e desenvolvimento rural: a percepção local da mudança”. In Simões, O. e Moreira, J. (org.): Actas do VII Colóquio Ibérico de Estudos Rurais. Coimbra, EESA, 13 pp.

CCRC (2002): Aldeias Históricas de Portugal. Um Património com Futuro. Coimbra, Comissão de Coordenação da Região Centro, 27 pp.

Ferreira, T. (2006): "Modelos de financiamento. Factor estratégico de desenvolvimento do turismo sustentável”. Revista Turismo \& Desenvolvimento, no 6, pp.133-137.

Hall, C. M. (2008): Tourism planning: policies, processes and relationships. Essex, Pearson Education.

Hall, D., et al. (2003): New Directions in Rural Tourism. Aldershot, Ashgate.

Henriques, C. (2003): Turismo, Cidade e Cultura. Planeamento e Gestão Sustentável. Lisboa, Ediçōes Sílabo.

Inskeep, E. (1991): Tourism Planning. An integrated and Sustainable Development Approach. New York, Van Nostrand Reinhold.

Ladeiras, A. et al. (2005): Plano Estratégico do Alto Minho. Santa Maria da Feira, IPDT.

Moreno, L. (1999): “A serra do Açor e o Piódão: refúgios de uma ruralidade recriada”. In Cavaco, C. (coord.): Desenvolvimento Rural. Desafio e Utopia. Lisboa, CEG, pp. 395-413.

Mota, A. et al. (2008): "Contributos para um modelo de planeamento estratégico em turismo". In Ayala Calvo, J. et al. (eds.): Conocimiento, innovación y empreendedores: camino al futuro, pp. 3087-3100.

Page, S. and Hall, C. (2003): Managing Urban Tourism. London, Prentice Hall.

Partidário, M. R. (2006): "O ambiente como factor de competitividade no turismo". In Careto, H. e Lima, S. (2006): Turismo e Desenvolvimento Sustentável - 1. Lisboa, GEOTA, pp. 71-74.

Price, M. (2007): Mountain Area Research and Management. Integrated Approaches. London, Earthscan. 